January 1999

\title{
Poor performance of health and population welfare programmes in Sindh: case studies in governance failure
}

Mehtab S. Karim

George Mason University

Shehla Zaidi

Aga Khan University, shehla.zaidi@aku.edu

Follow this and additional works at: http://ecommons.aku.edu/pakistan_fhs_mc_chs_chs Part of the Family Medicine Commons, and the Primary Care Commons

\section{Recommended Citation}

Karim, M. S., Zaidi, S. (1999). Poor performance of health and population welfare programmes in Sindh: case studies in governance failure. The Pakistan Development Review, 38(4), 661-688.

Available at: http://ecommons.aku.edu/pakistan_fhs_mc_chs_chs/208 


\title{
Poor Performance of Health and Population Welfare Programmes in Sindh: Case Studies in Governance Failure
}

\author{
MEHTAB S. KARIM and SHEHLA ZAIDI
}

\section{INTRODUCTION}

Over the past few years, the issue of what is meant by "good governance" has generated increasing attention and debate both at the national and international level [Streeten (1997)]. The role of state and how that role is to be exercised is appearing high on the agenda of politicians, policy-makers and academicians in the developing world. Governance has been defined by the World Bank as "the manner in which power is exercised in the management of the country's economic and social resources" [World Bank (1994)]. The somewhat narrow scope of this definition has been broadened in recent years to "the sum of the many ways individuals and institutions, public and private, manage their common affairs" [Commission on Global Governance (995)] The Human Development Report [UNDP (1999)] goes beyond these definitions and gives a much more radical notion of good governance, underpinning the importance of peoples' participation in shaping their own governance and development. This type of governance has been labeled as "humane governance".

A review of existing literature thus shows that governance has been interpreted to have different elements such as management of economic and social resources for development, formulation and implementation of policies, discharging of functions, accommodation of diverse interests towards cooperative action and above all, accountability to people and ownership by the people of the governance process.

In view of the above, one may ask what constitutes good governance for the health sector? Management of resources pertains to the concept of efficiency, a term appearing with increasing frequency in global literature on health care reforms; policy formulation and discharging of functions allude to the objective of effectiveness which itself has a wide scope encompassing relevance, quality and availability of health care; while "humane governance" brings in the notion of community participation and accountability with regards to decision-making and delivery of health care. The concept of equity, though not directly brought out in the above definitions, has been

Mehtab S. Karim is Associate Professor and Head of Reproductive Health Programme and Shehla Zaidi is Senior Instructor, Health Systems Division, Department of Community Health Sciences. The Aga Khan University, Karachi.

Authors' Note: Submitted for publication in The Pakistan Development Review. An earlier version of this paper was presented in the 15th Annual General Meeting of Pakistan Society of Development Economists, November 1999. 
included by us in applying governance to health care issues.

This paper attempts to analyse strengths and weaknesses of public sector governance in Sindh in the health and population sectors. It first provides a profile of Sindh, then moves on to describe the government's health and population welfare programmes, before focusing on governance issues at systemic, programmatic and organisational levels. For the purpose we use secondary data from various governmental and non-governmental sources. The last section provides recommendations aimed at both strategic and operational levels.

\section{THE SINDH CONTEXTS}

The Province of Sindh is confronted with multifaceted problems related to the delivery of health care and family planning services. These are further compounded by a high population growth rate (highest among the four provinces in the country), widespread illiteracy (particularly in the rural areas and specially among women), and a public sector health system whose performance has remained unsatisfactory. Although Sindh ranks as number one on the human development index compared to the other three provinces [Social Policy and Development Centre (1998)], and has high level of literacy in the urban areas (Table 1), the progress in health and demographic indicators is as poor as in other parts of the country (Table 2).

Table 1

Changes in Literacy Rates in Pakistan and Sindh by Area and Sex: 1972-98

\begin{tabular}{lccccccc}
\hline Sex and Area & \multicolumn{3}{c}{ Pakistan } & & \multicolumn{3}{c}{ Sindh } \\
\cline { 2 - 3 } & 1972 & 1981 & 1998 & & 1972 & 1981 & 1998 \\
\hline Male & & & & & & \\
$\quad$ Urban & 44.9 & 55.3 & 72.6 & & 54.5 & 57.8 & 72.1 \\
$\quad$ Rural & 22.6 & 26.2 & 47.4 & & 27.5 & 24.5 & 39.5 \\
$\quad$ Total & $\mathbf{3 0 . 2}$ & $\mathbf{3 5 . 0}$ & $\mathbf{5 6 . 5}$ & $\mathbf{3 9 . 1}$ & $\mathbf{3 9 . 7}$ & $\mathbf{5 6 . 6}$ \\
Female & & & & & & \\
$\quad$ Urban & 30.9 & 37.3 & 55.6 & & 38.4 & 42.2 & 57.1 \\
$\quad$ Rural & 4.7 & 7.3 & 20.8 & & 5.8 & 5.2 & 13.1 \\
$\quad$ Total & $\mathbf{1 1 . 6}$ & $\mathbf{1 6 . 0}$ & $\mathbf{3 2 . 6}$ & $\mathbf{1 9 . 2}$ & $\mathbf{2 1 . 6}$ & $\mathbf{3 5 . 4}$ \\
\hline
\end{tabular}

Source: Census of Population.

Table 2

Health and Demographic Indicators, Pakistan and Sindh, 1986-1997

\begin{tabular}{lccccc}
\hline & \multicolumn{2}{c}{ Pakistan } & & \multicolumn{2}{c}{ Sindh } \\
\cline { 2 - 3 } \cline { 5 - 6 } & 1986 & $1996-97$ & & 1986 & $1996-97$ \\
\hline $\begin{array}{c}\text { Infant Mortality Rate } \\
\text { (per 1000 Live Births) }\end{array}$ & 106 & 105 & & 108 & 99 \\
$\begin{array}{c}\text { Total Fertility Rate } \\
\text { (per Woman) }\end{array}$ & 6.9 & 5.4 & & 6.7 & 5.0 \\
\hline
\end{tabular}

Sources: 1986, Pakistan Demographic Survey.

1996-97, Pakistan Integrated Household Survey. 
To understand the factors behind the poor progress, it is important to first understand the demographic, economic and ethno-cultural peculiarities of Sindh, which set it apart from the other provinces in the country. It is worth noting that while only 35 percent of Pakistan's population is classified as urban about half the population of Sindh lives in the urban areas. This is due to the circumstances following the emergence of Pakistan as an independent country in 1947, when urban areas of Sindh in general and Karachi in particular received substantial number of migrants from India [Karim (1999)]. In the following decades, the influx from both within and outside the country continued especially to Karachi, which was established as Pakistan's capital and the major industrial and financial centre of the country [Selier and Karim (1986)]. Thus, Sindh's population has been increasing at a much faster pace than the overall population of Pakistan (Table 3). Within Sindh, growth patterns were substantially different. For example, the proportion of the urban population increased substantially from 29 percent in 1951 to 49 percent in 1998, as compared to 17 to 35 percent in Pakistan.

Table 3

Population Increase in Pakistan and Sindh and Percent of Population by Areas: 1951-98

\begin{tabular}{|c|c|c|c|c|c|c|}
\hline \multirow[b]{2}{*}{ Year } & \multicolumn{2}{|c|}{$\begin{array}{l}\text { Population } \\
\text { (in Millions) }\end{array}$} & \multicolumn{2}{|c|}{$\begin{array}{c}\% \text { Annual } \\
\text { Population } \\
\text { Growth Rate }\end{array}$} & \multicolumn{2}{|c|}{$\begin{array}{c}\% \text { of Population } \\
\text { Urban }\end{array}$} \\
\hline & Pakistan & Sindh & Pakistan & Sindh & Pakistan & Sindh \\
\hline 1951 & 33.7 & 6.1 & - & - & 17.8 & 29.2 \\
\hline 1961 & 42.9 & 8.4 & 2.44 & 3.25 & 22.5 & 37.8 \\
\hline 1972 & 65.3 & 14.2 & 3.89 & 4.89 & 25.4 & 40.4 \\
\hline 1981 & 84.2 & 19.0 & 2.86 & 3.29 & 28.2 & 43.4 \\
\hline 1998 & 130.6 & 30.0 & 2.47 & 2.72 & 32.5 & 48.9 \\
\hline
\end{tabular}

Thus, we find that the urban areas of Sindh are densely populatedcomprising of migrants from various parts of the subcontinent as well as from within Pakistan - and are the industrial and economic hub of the province. On the other hand, the rural areas are characterised by sparsely populated and scattered villages, having a strongly feudal agrarian society. In terms of civic infrastructure, though progress has been made in the provision of roads, electricity, schools and health facilities in the rural areas, many of the more remote areas are still without basic infrastructure. The urban areas, though well supplied with basic amenities, have suffered due to migration from other provinces, particularly during the past three decades. This has resulted in rapid growth of katchi abadis as well as has put pressure on basic urban services. Again, in terms of education, great disparity is found between the urban and rural areas, with female literacy of 57 percent in the former as opposed to merely 13 percent in the latter. Similarly, data collected in 1994 suggest an yearly household income per capita of Rs 5,550 in the urban areas 
of Sindh as compared to Rs 3,200 in the rural areas [Karim et al. (1998)].

In this background, with the help of most recent data, in the following section we examine the current situation regarding the governmental services in Sindh, with particular reference to governance issues related to the Health and Population Welfare departments.

\section{GOVERNMENT'S HEALTH PROGRAMME}

The health system of the province is traditionally geared towards a curative health facility based approach with attention towards preventive care and outreach services being a more recent phenomenon. The Ministry of Health is assisted by several international agencies such as the WHO, UNICEF etc, in planning and implementation of preventive programmes. Most of them are however, vertical in nature and are directly controlled by the federal government. Intensive efforts by the government are currently underway through various vertical programmes on immunisation, tuberculosis, control of diarrheal diseases, nutrition etc; several in-service training programmes; training of traditional birth attendants and, social mobilisation of communities.

The Government's health facilities network in the province is extensive, comprising of close to 4,000 health institutions of every possible variety, such as Teaching, Civil, District and Taluka Hospitals, Rural Health Centres (RHC), Basic Health Units (BHU), maternity homes, MCH centres, dispensaries, sub-health centres, urban health centres/units, T.B. clinics and school clinics. At present, different government owned health care facilities have a total of over 13,000 hospital beds and the Province has 687 BHUs and 90 RHCs (Government of Sindh, 2000). Thus, one hospital bed is available for about 2,300 persons, one nurse for 6,000 persons and one BHU/RHC for about 21,500 of the rural residents. These services are inadequate for reaching the total population, particularly in the rural areas, where settlements are highly scattered and means of communication insufficient.

For a person requiring medical attention in the rural areas, the first-contact unit is a BHU. Each BHU is staffed by a Medical Officer, while paramedical staff is expected to provide outreach health services for the surrounding areas. Outreach maternal and child health services are supervised from the BHU through a network of Lady Health Workers (LHW). The LHW Programme launched in 1994 is a major initiative of the federal Ministry of Health aimed at preventive and promotive health care through village based female workers. On paper at least, one LHW is assigned to each village providing essentially preventive care and some simple curative care to a population of 500-1000 persons.

The RHC is the next level of facility and provides referral support to surrounding 4-10 BHUs. The staff comprises 2-3 medical officers, a dentist, a chest specialist, a female doctor and 6-8 paramedical staff including lady health visitor, female health technician, laboratory assistant and male technician. The BHUs and the RHCs are the 
first contact for the rural population, while secondary care is provided by Taluka hospitals (located at sub-divisional level) and by District hospitals. While RHCs and BHUs are run and managed by DHOs, the Taluka and District hospitals fall under the administrative control of the provincial Health Department. The provincial counterpart of the Basic Health Services Cell was supposed to play a prominent role in the delivery of basic health services but now its role has been reduced to approving physical facilities. The vertical programmes, which include the bulk of preventive care plus the LHW programme, are federally controlled and have directorates at the provincial level. However, integration of the vertical programmes takes place at the health facility level.

In the urban areas, local councils have their own system of health services, but due to technical and financial constraints, they have established only a few MCH centres and dispensaries which are run parallel to the provincial health system. These are in addition to facilities run by the provincial Health Department. In large towns and cities such as Karachi, the local government also runs large tertiary care hospitals such as Abbasi Shaheed Hospital (now attached to a medical college) and Sobhraj Maternity Home. Health facilities run by the federal government, such as the Jinnah Hospital (JPMC) are also found in the metropolis. Aside from this, other government departments also have their own dispensaries, clinics and hospitals. Thus, urban areas have several parallel systems of government health facilities.

A large and expanding private health network consisting of hospitals, maternity homes and clinics in the urban areas is found. The private health services which are dominated by general practitioners, dispensers and pharmacy and other nonpharmacy retail outlets for drugs, have also made inroads into the rural areas. In addition, there are hospitals and clinics operated by trusts, foundations, welfare associations, missionaries and NGOs operating in the cities, towns and peri-urban areas. These facilities however, have no coordination with those owned by the government.

The Department of Health is expected to monitor the performance of its health facilities through a National Health Management Information System (HMIS). So far extensive funds and foreign expertise have been spent on the development and installation of this system which is considered one of the leading models for first level care facilities in the developing world. All health facilities report on a monthly basis and data is computerised and aggregated at the district level. Further compilation takes place at the divisional and provincial levels. The system is also designed to report on information related to personnel management, trainings, physical inventory and condition of health facility. However, so far no evaluation has been carried out to assess the effectiveness of HMIS in Sindh.

The government also runs development programmes in both the health and population welfare sectors, the largest amongst which is the Social Action Programme (SAP). The Programme was started in 1992-93 and aims at providing population welfare services, primary health care, primary education and rural water supply and sanitation to the under-served population. The project is a multi-donor consortium 
with a special focus on improving the quality and coverage of services and has a special emphasis on increasing the recurring expenditure. Overall, 19 percent of SAP funds are allocated towards primary health care. Another development project is the Family Health Project (FHP) which was started in 1993 with support from the World Bank. It is being implemented by the Department of Health. FHP aimed at strengthening the government health system through improving district management, providing in-service training to senior and mid-level health personnel, female health staff development and improvement of MCH services.

\section{ISSUES RELATED TO GOVERNMENT'S HEALTH SYSTEM}

\section{Low Utilisation of Governmental Health Services}

Despite the government being the largest institutional provider of health services, an assessment of the utilisation rates shows an increasing dominance of the private sector. As shown in Table 4, in urban as well as in rural areas, a large majority (about two-thirds) of those who fall ill prefer to seek treatment at private facilities, while less than one-fourth seek care at government facilities. In Karachi, utilisation rate of government facilities is even smaller.

A cross-district comparison carried out in 1997 [Aga Khan University and Sindh Health Development Centre (1997)], showed a range of utilisation of government health facilities between 14-31 percent, with notable exceptions seen in Mithi and Thatta districts, where 79 and 47 percent of the population respectively, was utilising government services. This could probably be due to the fact that both Mithi and Thatta are amongst the extremely under-developed districts of Sindh [Ghaus (1996)] where private practitioners have as yet not made much inroads. These results are in general comparable to the national level data obtained in the 1994 National Health Survey, which show that overall only 21 percent of the national population accessed government services with little variation seen across rural versus urban, gender or age groups [Pakistan Medical Research Council (1998)].

Table 4

Place of Treatment for those Reported Ill during the Past Two Weeks by Area, Sindh, 1994

\begin{tabular}{|c|c|c|c|c|}
\hline \multirow[b]{2}{*}{ Place of Treatment } & \multicolumn{3}{|c|}{ Secondary } & \multirow{2}{*}{$\begin{array}{c}\text { All } \\
\text { Sindh } \\
\end{array}$} \\
\hline & Karachi & Cities & Rural & \\
\hline Self/Pharmacists/Unqualified Person & 26.8 & 4.4 & 6.1 & 11.6 \\
\hline Private Dispensary/Clinic/Hospital & 52.6 & 73.0 & 67.1 & 64.1 \\
\hline Govt. Dispensary/Clinic/Hospital & 17.3 & 22.3 & 26.0 & 23.0 \\
\hline Others (like Hakim, Faith Healer etc.) & 3.3 & 0.3 & 0.8 & 1.3 \\
\hline Number of Persons Reported Ill & 7,724 & 2,287 & 15,768 & 28,014 \\
\hline
\end{tabular}

Source: Sindh Maternal and Infant Mortality Survey, 1994. 


\section{Impact of Preventive Services}

Preventive services though poor, in terms of coverage, are still provided mainly by the public sector. These services include immunisation, control of communicable diseases, maternal and child care etc. No programme has as yet been started for control of non-communicable diseases. The overall immunisation rate for under-five children in Sindh is low at 35 percent as reported in Pakistan Integrated Household Survey [Federal Bureau of Statistics (1997)] which was even lower in the rural areas of Thatta at 22 percent [Aga Khan University (1994)]. The overall immunisation coverage in the district was 28 percent however, most of the children (96 percent) were vaccinated by the Health Department personnel.

On the maternal health side, a majority of deliveries in Sindh are still being performed at homes and only 8 percent in government health facilities (Table 5).

Table 5

Percentage Distribution of Births by Year of Delivery, Place of Delivery and Area, Sindh, 1994

\begin{tabular}{|c|c|c|c|c|}
\hline \multirow[b]{2}{*}{ Year of Delivery } & \multicolumn{4}{|c|}{ Place of Delivery } \\
\hline & Home & $\begin{array}{c}\text { Private } \\
\text { Hospital/ } \\
\text { Clinic }\end{array}$ & $\begin{array}{c}\text { Government } \\
\text { Hospital/ } \\
\text { Clinic }\end{array}$ & All \\
\hline & \multicolumn{4}{|c|}{ Karachi } \\
\hline Before 1985 & 53.1 & 30.0 & 16.9 & 55.8 \\
\hline $1985-89$ & 43.6 & 36.5 & 19.9 & 25.6 \\
\hline $1990-91$ & 40.9 & 38.3 & 20.8 & 10.1 \\
\hline $1992-94$ & 37.3 & 42.2 & 20.5 & 8.5 \\
\hline All Years & 48.1 & 33.5 & 18.4 & 100.0 \\
\hline \multirow[t]{2}{*}{ Number of Pregnancies } & 20,401 & 14,208 & 7,803 & 42,413 \\
\hline & \multicolumn{4}{|c|}{ Secondary Cities } \\
\hline Before 1985 & 83.2 & 9.5 & 7.3 & 46.7 \\
\hline $1985-89$ & 76.6 & 13.6 & 9.8 & 27.9 \\
\hline $1990-91$ & 73.6 & 16.7 & 9.7 & 12.3 \\
\hline $1992-94$ & 69.5 & 19.2 & 11.3 & 13.2 \\
\hline All Years & 78.1 & 13.0 & 16.9 & 100.0 \\
\hline \multirow[t]{2}{*}{ Number of Pregnancies } & 24,314 & 4,047 & 5,261 & 31,132 \\
\hline & \multicolumn{4}{|c|}{ Rural } \\
\hline Before 1985 & 96.6 & 2.3 & 1.1 & 40.4 \\
\hline $1985-89$ & 94.8 & 3.5 & 1.7 & 29.9 \\
\hline $1990-91$ & 93.0 & 4.6 & 2.4 & 14.7 \\
\hline $1992-94$ & 91.9 & 5.5 & 2.6 & 15.0 \\
\hline All Years & 94.7 & 3.6 & 1.7 & 100.0 \\
\hline \multirow[t]{2}{*}{ Number of Pregnancies } & 65,983 & 2,508 & 1,185 & 69,676 \\
\hline & \multicolumn{4}{|c|}{ All Sindh } \\
\hline Before 1985 & 78.2 & 13.7 & 8.1 & 46.3 \\
\hline $1985-89$ & 77.1 & 14.5 & 8.4 & 28.2 \\
\hline $1990-91$ & 76.9 & 15.0 & 8.2 & 12.8 \\
\hline $1992-94$ & 74.6 & 16.8 & 8.5 & 12.7 \\
\hline All Years & 77.3 & 14.5 & 8.2 & 100.0 \\
\hline Number of Pregnancies & 110,710 & 20,767 & 11,744 & 143,221 \\
\hline
\end{tabular}

Source: Maternal and Infant Mortality Survey- Sindh, 1994. 
While in cities, the situation has improved recently as deliveries are being conducted away from home, but largely at private facilities. In the rural areas still over 90 percent are performed at home and less than 3 percent at government facilities. Apparently most of the deliveries at homes are performed by the untrained traditional birth attendants (TBAs). The government has an ongoing TBA training programme to introduce safe delivery practices for home based deliveries. Conflicting reports are found about success of the TBA training programme and a comprehensive assessment still needs to be undertaken. Furthermore, even if TBA training has been successful at the grassroots level, it needs to be supplemented with emergency obstetric services which are lacking in almost all government health facilities in the rural areas.

The LHW programme is presently the most ambitious programme of the Ministry of Health in terms of providing coverage to under-served population. By the end of 1996, 43000 LHWs had been deployed each covering between 500-1000 population, with a final enrollment target of 100,000 LHWs [World Bank (1997)]. However, a survey in Karachi, District South [Aga Khan University and Sindh Health Development Centre (1997)], showed that while the majority of the population (63 percent) is covered by LHWs, only 28 percent of the covered population knows the name of the LHW. Field observations from both urban and rural areas suggest that in several places non-local LHWs have been recruited on political grounds, with the result that visits by them to catchment areas are few and far between. Local recruitment is a key factor in the success of this programme. A detailed evaluation of the LHW programme is needed to identify its strengths and weaknesses.

\section{Failure to Address Non-communicable Diseases}

The epidemiological transition underway in Pakistan leading to the emergence of chronic disease has been ignored at both planning and implementation levels. According to estimates [World Bank (1997)] nearly 38 percent of the total burden of disease in Pakistan is due to non-communicable causes, while injuries contribute an additional 12.5 percent. According to national level estimates [Pakistan Medical Research Council (1994)] 21 percent of urban and 16.5 percent of rural dwellers over the age of 15 years have hypertension. Of these, most are unaware of the problem and only a third receiving treatment have controlled blood pressure. The scenario is similar for diabetes. Injuries are projected to be the second most common cause of death and disability in developing countries by the year 2020. In Karachi, the rate of road traffic accidents is 190/100,000 but this figure would probably be much higher with proper reporting [Ghaffar et al. (1999)]. Other injuries such as burns, falls, gunshots and suicides still have to be accounted for.

Given the age distribution of the population and the fact that nearly 50 percent of Sindh's population resides in the urban areas, the neglect of the government in addressing non-communicable health problems is appalling. None of the first and 
secondary level health facilities are equipped to handle these problems, nor they have basic medications included in the essential list of drugs supplied. The only recourse is to teaching hospitals located in Hyderabad and Karachi which are over-crowded and poorly managed and often depend upon philanthropic assistance. So far no awareness and prevention programme has also been launched. The National Health Monitoring Information system is also not designed to report the problems of non-communicable diseases. Thus, the existing trend of rapid growth in chronic diseases and injuries is going to put added burden on an already poorly functioning health system.

\section{Weaknesses in the Referral System}

Patients mostly tend to crowd into the rural health facilities for outpatient visits, rather than utilising the more peripherally located BHUs, thereby pre-empting the referral chain. A study of BHUs and RHCs in Sindh suggested that average number of patients seen in a BHU was disappointingly low at 8 patients per day while the corresponding figure for RHC was much higher at 58 patients per day [Planning and Development Department (1990)]. In the case of in-patient attendance it was noted that bed occupancy for RHCs was very low at 9.6 percent with most patients tending to bypass RHCs, probably in favour of tertiary care district hospitals or large teaching hospitals located in cities. The fact that most RHCs do not provide services round the clock could probably be the major contributing factor behind low inpatient attendance.

\section{Access to Health Care}

Access to health care is determined by a combination of physical, cultural and financial factors. Government owned facilities are often situated away from the town center on donated patch of land as compared to the private clinics which are more conveniently located within a populated area and are easy to reach by public transport. The public sector facilities are also perceived to have poor "quality" of care in terms of non-availability of staff, medicines, physical conditions and condescending staff attitude as compared to the private sector.

The growing contribution of the private sector is proof enough that people are willing to pay for their health care, provided they get quality care. This is corroborated by the fact that of the 3 percent of GDP spent on health care, only 0.8 percent is spent by the government while the remaining is mostly contributed by the private sector. Thus, the burden of health care essentially falls on the household level with only the very poor utilising the government's primary care facilities. On an average, a household spends almost 10 percent of yearly income on health care (Table 6). Households in rural Sindh, despite having a lower monthly income, spend proportionately more on health care (12 percent) as compared to their counterparts in Karachi where expenditure on health care is reported as 6.8 percent of household income [Karim et al. (1998)]. However, higher expenditure by the rural households could also be attributed to high transportation cost from the rural to urban areas, where most of the private health facilities are located. 
Table 6

Annual Household Expenditure on Health Care and other Items by Area, Sindh, 1994

\begin{tabular}{|c|c|c|c|c|}
\hline \multirow[b]{2}{*}{ Percentage of Income Spent on } & \multicolumn{3}{|c|}{ Secondary } & \multirow{2}{*}{$\begin{array}{c}\text { All } \\
\text { Sindh }\end{array}$} \\
\hline & Karachi & Cities & Rural & \\
\hline Food Items & 58.5 & 58.0 & 57.9 & 58.2 \\
\hline Clothing & 8.9 & 16.5 & 16.3 & 13.4 \\
\hline Health Care & 6.8 & 10.9 & 12.2 & 9.8 \\
\hline Miscellaneous & 25.8 & 14.6 & 13.6 & 18.6 \\
\hline Total & 100.0 & 100.0 & 100.0 & 100.0 \\
\hline $\begin{array}{l}\text { Median Expenditure on all } \\
\text { items (in Rs per Annum) }\end{array}$ & 3,000 & 2,000 & 1,500 & 2,000 \\
\hline Median Income (in Rs per Annum) & 3,500 & 2,166 & 1,600 & 2,000 \\
\hline
\end{tabular}

\section{Problems with the Planning Process}

Although health is a provincial subject, the dominance of the federal government in this sector has grown over the years. This could be attributed to increase in number of vertical programmes and expansion in development projects both of which are controlled by the federal Ministry of Health. This essentially leaves provision of curative care, health facility planning and human resource development in the purview of the provincial Health Department. With the scope of development projects being expanded to include re-structuring of the health care system, these areas are also becoming vulnerable to centralised and donor driven policies. Given this context, it is unclear how autonomous is the province with regards to health care.

Within the province, the number of departments involved in the provision of health care services are multiple which besides the Health Department also include Social Welfare, Local Government, and Population Welfare departments. However, little inter-departmental coordination is found at the planning and strategic levels. This lack of shared understanding also extends to different sections working within the Health Department. The department consists of the health secretariat headed by the Secretary of Health and the directorate headed by the Director General, Health Services. While the secretariat is responsible for decisions at wider strategic level, the directorate oversees the overall operational management of health services. A lack of shared understanding often occurs between the two levels as to the boundaries between the two functions [Green et al.]. Thirdly, planning is perceived mainly as the development of PC-1 documents for capital schemes, such as development projects and is regarded as the domain of the Planning and Development Department (P\&D). Once a satisfactory project document has been prepared, there is little role left for P\&D, with the result that a gap is created between the planning and implementation process. Recurrent expenditures and activities, even if they are the spin-off of development projects, do not fall within the planning domain and are often subject to adhoc decisions taken at the secretariat level. 


\section{Problems Related to Governmental Health Care Expenditure}

Health care expenditure is traditionally classified into recurring and development expenditure, both of which depend upon multiple sources of financing. According to an analysis done by the Social Policy and Development Centre (1998), provinces in the early 1970s were financing close to half of the recurring social sector expenditure from their own sources. These mainly compromised provincial tax revenues and user charges to a lesser extent. Most of the remaining amount was contributed through federal fiscal transfers (Table 7). Over the years, this dependence on federal transfer has increased making social services, including health care, extremely vulnerable to resource crunch at the national level.

The dependence on the federal governments' support ultimately leads to cutbacks in the social sector, including health care expenditure. As shown in Table 8, the provincial health budget of Sindh, shows a downward trend from 8.5 percent in 1993-94 to 7.0 percent in 1996-97 [World Bank (1997)]. This cutback in health expenditure is associated with the unfavourable National Finance Commission Award for Sindh, which caused a drastic reduction in social sector and development related funds. In contrast, health expenditure of other provinces has demonstrated an upward trend, with Balochistan showing the greatest increase in allocation from 5.7 to 8.2 percent, during this period.

Table 7

Trends in Sources of Financing of Recurring Expenditure on Social Sectors by Provincial Governments, 1972-98 (All Figures in Percent)

\begin{tabular}{lccccccc}
\hline & $1972-73$ & $1977-78$ & $1982-83$ & $1987-88$ & $1992-93$ & $1996-97$ & $1997-98$ \\
\hline User Charges & 9 & 4 & 4 & 4 & 4 & 3 & 3 \\
Fiscal Transfers & 47 & 72 & 79 & 82 & 87 & 88 & 86 \\
Own Tax Revenues & 34 & 23 & 17 & 9 & 9 & 9 & 11 \\
Borrowings & 10 & 1 & - & 5 & - & - & - \\
Total & 100 & 100 & 100 & 100 & 100 & 100 & 100 \\
\hline
\end{tabular}

Source: SPDC Annual Review 1998.

Table 8

Health Expenditure as Percentage of Total Expenditure, by Province, 1993-94 and 1996-97

\begin{tabular}{lcc}
\hline Province & $1993-94$ & $1996-97$ \\
\hline Balochistan & 5.7 & 8.2 \\
Punjab & 7.4 & 8.0 \\
NWFP & 7.6 & 8.7 \\
Sindh & 8.5 & 7.0 \\
\hline
\end{tabular}

Source: Pakistan, Towards a Health Sector Strategy, The World Bank (1997). 
As a result of the cutback in Sindh, the health care budget is being increasingly transformed into a salary budget. With the dwindling of funds for drugs, supplies, equipment etc, the quality of service in an institution already chronically short of these necessities, becomes increasingly sub-standard, causing a further reduction in utilisation rate. Another important area affected is the mobility of government health staff, since transportation costs are especially high in the rural areas. Therefore, both necessary outreach activities at the village level by health facility staff as well as routine supervisory visits to health facilities by district health managers have been substantially reduced. Unless non-salary inputs are increased, it is doubtful whether a meaningful improvement in health services can be brought about.

Aside from the shortfalls in recurrent expenditure, the dependence upon federal support also leaves little room for health care initiatives and planning at the provincial level. With the current planning process working on a contingency footing to meet the budget deficit, the emerging health care challenges and community needs get delegated to the back burner. Lastly, with most of the resources being controlled at federal level, there is also an increasing shift towards centralisation of authority.

\section{Problems Related to Development Projects}

The Sindh Government initiated the Family Health Project (FHP) in 1992. It was funded with the World Bank's support and is being implemented by the Health Department. The Social Action Programme (SAP) implemented a year later, basically with similar objectives. However, both SAP and FHP have remained independent from each other and indeed have overlapped in several areas leading to duplication of efforts. According to SPDC Annual Review 1999, SAP has failed to meet several of its objectives. An assessment of FHP by AKU showed that while structural changes intended by the project have failed to take root, certain components of service delivery have improved in the project areas. However it is uncertain how long lasting will be these gains after winding up of the project is completed. In a recently conducted review at the end of project, it was reported that FHP has only partially met its objectives [Aga Khan University (2000)].

Both FHP and SAP, like other development projects, were primarily developed in consultation with the Planning and Development Department (P\&D) with considerable input from donor agencies, but once the PC-1 document was developed there was little actual coordination with $\mathrm{P} \& \mathrm{D}$, thereby producing a gap between planning and implementation. For a development project a separate set-up in the form of a project implementation unit, is usually established. As a result the project runs independently of the Health Directorate. Many of the development initiatives deal with the existing health system but because of lack of coordination with the Health Directorate, they end up as long term vertically managed initiatives and fail to get institutionalised into the existing system. Another such example is the Health 
Management Information System which was developed and initially implemented by the Child Survival Project. But even after the winding up of the project in 1994, it is being run as a vertical activity with responsibility shifted to successive development projects. Like many other projects, its evaluation has yet to be conducted.

Overall development expenditure, including SAP, is heavily dependent upon federal grants and loans, which in turn rely upon assistance from foreign donor agencies. By 1996-97, SAP expenditures at the national level amounted to 2.13 percent of the GDP, but were drastically pruned, after the 1997 NFC award, to 1.78 percent in 1997-98. This dependence causes delays and interruptions in the implementation of projects due to creation of budgetary shortfalls. A criticism often faced by development projects is of mismanagement, especially of physical inputs. Though uncertainty and shortfall of funds are a contributing factor, other factors also play a role, such as lack of a financial monitoring system, slow disbursement of funds and time consuming purchasing process which result in delayed provision of physical inputs.

Lastly, even if SAP and other special projects deliver the promised results, the sustainability issues would still remain. While development projects may have contributed towards improvement of services, institutional issues of governance also need to be simultaneously addressed, to make any long lasting change. On the financial side, the huge investment in services will require a corresponding degree of recurring expenditure on an ongoing basis. Three important questions remain to be answered; (i) is the provincial government ready to step into the breech after the end of donor assistance and federal support?; (ii) even if federal support continues, will the provincial government be able to meet the upkeep expenses of development initiatives, specially in a worsening economic scenario? and; (iii) even if some degree of federal support is mustered, will not this increased reliance on outside funds create further centralisation of the health care system?

\section{Problems Related to Staffing}

The practice of promotion based on years of service rather than job performance, leaves little incentive for staff to work and encourages low output, staff absenteeism and neglectful attitude towards patient/ community. This is further compounded by the low wages received, which leaves little recourse to staff but to develop a side practice.

Field observations and survey data show that while most sanctioned staff positions at health facilities are filled, the actual attendance especially by doctors falls much below expectations - in extreme case a RHC having more than 20 staff members, had a working strength of only 3-4. According to estimates, as much as 60 percent of doctors are usually not found at their place of posting and have been able to get themselves "detailed-to-work" at hospitals particularly in large cities. Posting of non-local personnel may be one of the factors contributing towards absentiesm. 
According to the health facility survey in Sindh [Planning and Development Department (1990)], only 46 percent of the male doctors and 48 percent of female doctors posted in RHCs were from the local area. The figures are even worse (19 percent) for Lady Health Visitors who form the backbone of maternal and child care services. The shortage of female doctors and particularly female paramedical staff, restricts the access of female patients to health facilities leading to failure of reproductive health services. Though sanctioned strength also falls short of requirements, most of the existing female staff seek urban or periurban postings and are unwilling to be posted to the remoter areas. Being in high demand, several of them maintain a thriving private practice in the towns of rural districts. Amongst the staff regularly attending health facilities, most do so only during the morning hours and usually maintain a private practice in the evening. It was noted that community members mostly prefer to go to the private clinic rather than seek care from the same doctor at a government owned facility.

Frequent transfers of government staff is another factor impeding improvement in health care. Transfers are especially common at the officers level, the higher the post more frequent is the shuffling. Most of the transfers are on political basis and take place due to change in provincial political set-up or are brought about to appease favourites. This frequent change over, causes disruption in pace of work with development projects often being the hardest hit

\section{Imbalance in Human Resource Development}

The unfavourable paramedic: doctor ratio has long been an issue in the delivery of primary health care services. In the province, currently there are about 46 registered doctors per 100,000 population, while the number of nurses is only about 15 per 100,000 and that for LHV is 2 per 100,000. These figures underline the gross distortion in the health care system particularly when there is still a critical need to expand primary health care services. While the accepted norm is one doctor to 7 nurses, about 1,200 doctors per year are produced by government medical colleges, as compared to only 300 nurses annually. This trend is further widening the gap. At a time when private medical colleges are rapidly emerging, there is urgent need to prioritise the type of human resources needed for effective health care delivery and channelising of resources in the appropriate direction.

It is not surprising that the type of training given to doctors, nurses and paramedical staff is also of a curative nature. Courses in training institutions do not emphasise the need and feasibility of incorporating community health and preventive and promotive care (exceptions are a few privately owned institutions). At present there are three Public Health Schools in Sindh (one each at Hyderabad, Sukkur and Karachi), with an annual output of over 100 LHVs. There are three health technician's schools, one each at Hyderabad, Sukkur and Mirpurkhas. A dozen nursing schools (including some in the private sector) are spread over the province, with most located in Karachi. 
Given the centralised locations of the training schools, it is difficult for candidates from rural areas, especially females, to have access to training. An additional constraint to an effective recruitment programme is the present qualification needed to acquire admission and/or training for auxiliary staff. With about half of Sindh's population living in the rural areas, which lack proper education facilities, many likely female entrants are unable to meet the admission requirements.

\section{Fragmented Urban Health Services}

One of the major problems in the government's health system is that of line of control. Urban areas despite having 40-50 percent of total population and a multiplicity of institutional providers including both local, provincial and federal government outlets, are without a coherent health care plan. At both strategic and operational levels, it leads to fragmentation in the planning process and subsequent wastage of resources through overlapping services. These result in patchy coverage to the population, with no single institution being accountable for health care of the people.

\section{Lack of Regulation of the Private Sector}

The private sector, especially in the urban areas, has become the main health provider in Pakistan, and Sindh is no exception. However, no regulatory framework exists which could account for the role of the private sector in the health care delivery. In many areas, unqualified "doctors" have set up clinics and are providing medicines to the people who visit them frequently. Though qualified doctors are required to renew their professional license with the Pakistan Medical and Dental Council every five years, no mechanism exists for certification of professional skills nor is there a system of refresher courses to upgrade clinical skills. Provider induced demand for unnecessary use of medicines, especially injectables, has risen in the general population along with a simultaneous increase in the use of high technology such as CT scans, ultrasound and MRIs. What makes regulatory action particularly difficult is that no centralised information exists regarding number of doctors, clinics or hospitals in the private sector, their fee structure and standard of service, so that one could plan for the future.

\section{Poor Community Involvement}

The need for community involvement has been featuring on policy documents over the past decade and has been highlighted repeatedly in development plans. However, on ground, progress is almost non-existent. One of the reasons is that bureaucrats and service providers responsible at the operational level, have as yet little concept of community participation and lack the skills regarding the process of mobilisation and involvement. Secondly, policy documents are in themselves vague about the extent of community participation, which is often taken as synonymous to helping the health providers in achieving their service targets. The concept of accountability and ownership is still missing. 
During mid to late 1990s, an effort was made to involve community representatives through Village Health Committees (VHCs) at health facility level and, through District Health Management Teams (DHMT), at the district level. These initiatives were taken by the Family Health Project (FHP) as well as the Social Action Programme (SAP), but conceptualised and implemented independently of each other. Both the attempts at DHMT formation failed due to several constraints including lack of clarity on outcome, reluctance of government machinery to decentralise authority, lack of a legislative support framework and confusion created by implementation of both SAP and FHP driven DHMTs at the same time. The VHCs were initially created by SAP in the mid 1990s but the attempt was unsuccessful. This was followed by creation of VHCs by FHP towards the late 1990s which, with the exception of a few, have also been largely unsuccessful and are dominated by local influentials rather the than villagers themselves.

\section{POPULATION WELFARE}

Sindh is facing the dual problem of natural increase in population of 2.2 percent annually and, in addition, about 1 percent annually due to migration of people from other provinces. During the 1972-81 inter-censual period, the province recorded a population growth rate of 3.6 percent per annum (as compared to 3 percent for the country). The most recent survey suggests a total fertility rate of 5.0 per woman. These rates are high mainly due to an ineffective family planning programme with poor delivery of services, as reflected in a low contraceptive prevalence rate (CPR) of 23 percent. Given that about half the population of the province lives in the urban areas, this CPR is fairly low as compared to the province of Punjab (27 percent), India (41 percent) and Bangladesh (49 percent), all having fairly lower percentage of population living in urban areas. Recent survey data indicate that the natural growth rate of the population in the province has remained high : 2.7 percent in the rural and 2.6 percent in the urban areas [Hakim et al. (1998)]. Results of the Demographic and Health Survey conducted in 1990-91 indicated that in Sindh only 12 percent of currently married women in the age group 15-49 were using any method of contraceptives. The contraceptive prevalence rate since then has doubled [National Institute of Population Studies (1992)], however, it is still substantially low. Thus, the likelihood that Sindh' population growth rate will decline in the near future is remote.

\section{Role of the Family Planning Programme}

A very ambitious Family Planning Programme was launched in 1965 with complete government support and substantial financial assistance provided by the international agencies. The programme took into account the issues related to the rapid growth of population and sought to provide official, political, and financial support to the idea of family planning. In order to implement the programme, the Family Planning 
Scheme of 1965-70, laid down emphasis on personnel administration, logistic support and information, education and communication strategies, as well as prescribed priorities for manpower development with provision for monitoring and evaluation of the service delivery system. It was based on target oriented approach for which indigenous dais were considered the backbone of the programme.

The programme remained centralised, even after the break-up of one unit in 1970, [Rukunuddin and Cleveland-Hardee (1992)]. The programme strategy was, however, changed to an innovative approach of Continuous Motivation System (CMS). The subsequent evaluation of CMS indicated that field activities did not live up to the expectations due to casual selection of personnel, inadequate training, ineffective supervision, and non-acceptance of young, unmarried persons assigned at the grass-root level, to promote contraception and birth control. The failure of the CMS led the planners to the conclusion that the motivational activities carried out by the field workers did not get the adequate supplies of contraceptives to the potential users. Therefore, another strategy was adopted through contraceptives inundation approach in 1974. According to the Pakistan Fertility Survey of 1975, although over 75 percent of eligible women were aware about family planning methods, only 22 percent knew the source of information and services. The reason was attributed to poor administrative capabilities of the field staff and the lack of publicity campaign on the part of field functionaries. From 1977 to 1980, the programme did not get any attention from the Government due to the sensitive socio-political conditions in the country. Even during

Table 10

Knowledge and Use of Contraceptives among Currently Married Women in Reproductive Age-group, Pakistan and Sindh, 1990-1997 (All Figures are in Percent)

\begin{tabular}{|c|c|c|c|c|}
\hline & \multicolumn{2}{|c|}{ Pakistan } & \multicolumn{2}{|c|}{ Sindh } \\
\hline & $1990-91$ & $1996-97$ & $1990-91$ & $1996-97$ \\
\hline Know any Method & 77.9 & 94.3 & 74.4 & 95.4 \\
\hline Know any Modern Method & 77.2 & 93.4 & 73.9 & 95.2 \\
\hline Using any Modern Method & 9.0 & 16.9 & 9.1 & 17.0 \\
\hline Using any Traditional Method & 2.8 & 7.0 & 3.4 & 6.4 \\
\hline \multicolumn{5}{|l|}{ Currently Using } \\
\hline Pill & 0.7 & 1.6 & 0.7 & 1.1 \\
\hline IUD & 1.3 & 3.4 & 0.9 & 1.8 \\
\hline Condom & 2.7 & 4.2 & 3.4 & 4.9 \\
\hline Injection & 0.8 & 1.4 & 0.4 & 1.0 \\
\hline Sterlised & 3.5 & 6.1 & 3.5 & 8.2 \\
\hline Withdrawal & 1.2 & 4.6 & 1.3 & 5.2 \\
\hline Other & 1.6 & 2.7 & 2.1 & 1.2 \\
\hline
\end{tabular}

Sources: 1990-91 Pakistan Demographic and Health Survey; 1996-97 Pakistan Integrated Household Survey; and 1996-97 Pakistan Fertility and Family Planning Survey. 
the decade of the 1980 s, the programme generally received lip service, without making any efforts to improve the delivery system [Rukunuddin and Cleveland-Hardee (1992)].

Although a number of approaches were adopted to make family planning a success, the results however, remained poor. Amongst a host of reasons, one, which is often given by the programme personnel, relates to the programme never being allowed to function smoothly. However, such factors as supply orientation with weak demand creation, inadequate monitoring and unrealistic target setting and insufficient access to quality family planning services, particularly at the health outlets, and the lack of motivation among the programme personnel are also cited as the major reasons for the poor performance of the programme. For example, in a World Bank report (1993) on the Population Welfare Programme in Sindh, it was observed:

"The situation of the Department of Population Welfare in Sindh continues to cause grave concern. Despite the efforts of a few individuals, the output from the office is limited and staff morale seems low. In the (World Bank) mission's view, the time now seems appropriate for some determined action. This could take the form of a rapid management audit to assess the extent of the problems, and the seconding of key managers to put the Department back on track".

\section{Lack of Political Commitment and Administrative Support}

Besides, the programme has been suffering due to the lack of political commitment, constraints of funding in line with the requirements of planned targets, implementation bottlenecks, and limited access to rural communities in the absence of logistics and transport facilities. The programme also lacks a mutually supportive approach to build up a system of communication, mobilisation and health education regarding family planning along with delivery of basic services in an integrated manner. Furthermore, the extensive network of government health facilities does not support the programme framework in the public or the private sector. For example in the rural areas BHUs and RHCs are hardly used to provide family planning services.

Family Planning/Population Welfare has remained a federal government's programme throughout, whereby uniform policies are framed for all the provinces and areas, without giving due consideration to the cultural sensitivities and sociological, economic, demographic and political factors. If the provinces were to frame their own population policies, local input through participation from the political leadership and the public at large, would have provided the needed support to the programme at the grass root level.

\section{Weak Monitoring System}

Another problem relates to the distribution of contraceptives about which donor agencies as well as the Monitoring and Statistics wing of the Ministry of Population Welfare has raised repeated concerns. Consequently in an evaluation of 
the distribution and logistics of contraceptive done by the Population Council (1998), it was noted that although the distribution from the Central Warehouse House to the district stores was satisfactory, however the main difficulty is with the non-traceable stocks, particularly of condoms and pills. In most cases the sales proceeds were not deposited. Similarly at the service provider level there were serious inadequacies. Most of the field officers had lack of knowledge about the logistics and reporting procedures.

\section{New Initiatives}

During the past decade, several new initiatives were taken to increase contraceptive prevalence rates specially in the rural areas. For the purpose, in 1992, a Village Based Family Planning Workers (VBFPW) Scheme was introduced on pilot basis. Under the Eighth Five Year Plan this scheme was extended to cover over 13,000 villages for which 12,000 VBFPW have been recruited. These workers are expected to be married females between ages 18-50, with high school education and residents of the area where they are serving. However, in an evaluation of VBFPWs (Ministry of Population Welfare and the Population Council, 1995), nationwide the selection criteria were followed in 72 percent of the cases. Half of those who failed to meet the criteria were from Sindh, while adherence was over 80 percent in Punjab and NWFP. Over 42 percent of VBFPWs in Sindh were less than 25 years of age (12 percent in Punjab) 15 percent were unmarried (10 percent in Punjab); and 49 percent had below high school education (40 percent in Punjab). Interestingly 17 percent of VBFPWs in Sindh said that their employment had a negative effect on their status by working for family planning programme. In terms of their performance, while in Punjab an average VBFPW had visited 170 couples, in Sindh she had visited only 20 couples and about 5 percent had complete work plans (8 percent in Punjab). Record keeping was however, considered good in case of 56 percent of VBFPW in Sindh and 58 percent in Punjab. Similarly contraceptive prevalence rates in the areas covered were 24 percent in Sindh and 26 percent in Punjab, which had increased substantially over the past two years from 4 and 11 percent respectively in the rural areas of the two provinces.

\section{RECOMMENDATIONS}

\section{A. Revamping the Health Care System}

1. The expanding private sector is here to stay and its dominance in the health sector needs to be recognised by policy-makers. The tendency of ignoring its existence in the hope that the trend will reverse, can no longer be continued. Since the provision side of the government is weak, the policy-making arm will need to be strengthened to come up with successful public-private partnership mechanisms which at the same time do not jeopardise the interests of the disadvantage groups. Private provision could be financed through government 
sources to provide subsidised care to low income and other vulnerable groups. Furthermore, vertical programmes such as EPI, Family Planning, Tuberculosis Control etc, often supported by multilateral agencies such as WHO, UNICEF etc, need to be expanded to include the private sector which caters to most of the population.

2. While such efforts are underway, the simultaneous process of regulation of quality of care through licensing and certification of providers and their services must also be started and both short and long term targets set for completion of the process. An effective evaluatory framework of the earning capabilities of private doctors and hospitals also needs to be established. A formula has to be worked out to properly tax the private sector or requiring them to provide preventive care as well, without charging the beneficiaries.

3. Strategic level planning for urban areas aimed towards development of an Urban Health Plan needs to be initiated on a systematic footing with participation of all government departments (local, provincial, federal and others) involved in urban health care provision. Role of NGOs and other actors should also be explored in development of the plan through open dialogue. Secondly, centralisation of health care due to federal and donor driven vertical programmes and development projects, needs to be curtailed and separate directorates of vertical programmes should be abolished. Thirdly, the gap between planning and implementation needs to be reduced by enlarging the role of P\&D department from conceptualising of capital schemes to providing technical support for planning and monitoring of recurrent activities also. Lastly, better understanding between the health secretariat and directorate is needed to arrive at the decision making boundaries of each level.

4. Chronic diseases and injuries must be included as a priority agenda for action and research if premature deaths and years lost due to disability are to be avoided and health expenditure burden on both households and the public sector due to expensive curative care is to be curtailed. Proper reporting and documentation of cases as well as baseline surveys are needed as a first step to build an adequate database. Treatment and control measures targeted at control of diabetes, hypertension, cancer, injuries etc, must be urgently incorporated into all levels of the government's health system including dispensaries and BHUs. Creative partnerships could be created with the private sector for emergency service while avenues for piggybacking awareness and prevention programmes onto the existing outreach activities, such as the LHWs programme, could be explored.

5. A proper referral system needs to be put into effect especially to address imbalances in the use of different levels of care. Postings of specialists could be redistributed to ensure adequate staffing of district hospitals which could decrease the load on teaching hospitals. Other institutional measures can also be 
undertaken such as mandatory serving for specified period in rural areas for those who gain entrance to medical and technical colleges on rural reserved seats. Accreditation of well-functioning district hospitals as teaching units can be used as incentive for staff postings. Besides, creation of autonomous budgets for district hospitals and authority for revenue generation and local usage are also recommended for improving functioning of district hospitals. Lastly, criteria for referrals both for different levels of care and for inter-institution referral, needs to be developed given the ground realities.

6. With cut backs in social sector allocation in real terms, combined with growth in population, government services are fast becoming the option of last choice even for the lowest income strata. Overall health expenditure needs to be increased but must be simultaneously accompanied by institutional reforms in order to have a meaningful output. Within health allocation, the non-salary budget not only needs to be substantially increased but at the same time decentralised to district level if quality of service is to be improved. Funds from poorly performing development projects and redundant vertical programmes can be diverted to supplement this critical need.

7. Further investment in development projects needs to be urgently reviewed in the light of poor implementation and mismanagement of such projects due to institutional weaknesses and bureaucratic delays. The vertical nature of development programmes and over dependence on federal and donor support are harmful for provincial autonomy. Sustainability issue must also be kept in mind when planning, as in light of the squeeze on non-salary recurrent budget for existing activities, it is difficult to foresee how funds to bear the recurrent expenditure of development projects, will be mobilised.

8. The highly subsidised government's health sector cannot provide the quality care on the minimal budget provided, unless it is in a position to generate its own funds. While the urban based population which enjoys a higher per capita income is willing to pay high user charges to private practitioners, this is not necessarily possible for the poor and the rural people who are already overburdened due to the lack of transport and communication facilities, and absence of basic services. It is recommended that some degree of user fee at tertiary care hospitals be introduced on an experimental basis with the principal aim being improvement in quality of services and decreasing over utilisation rather than cost recovery. A sliding fee structure can be used particularly for inpatient admission. This exercise first needs to be preceded by a careful study assessing the income elasticity of demand for hospital services and devising a formula for levying user charges.

9. Staff reforms are urgently needed to improve the effectiveness, efficiency and transparency of the existing system. Promotion based upon performance rather than seniority, dismissal of absentees and salary increase of the remaining staff 
as a disincentive for corruption, are proposed to increase work efficiency and induce a conducive atmosphere towards delivery of services. Curtailment of frequent transfers is also recommended and can be taken without incurring of expenditure. Lastly, district heath officers and medical superintendents of hospitals need to be delegated powers regarding postings, transfers and suspensions if government health facility services are to improve.

10. Though improvement in preventive services is underway, the pace of improvement is slow. It is imperative that rapid gains be made, particularly in the rural areas, where government is the sole provider and where other sources are unlikely to bridge the gap.

11. Given the diverse nature of rural settlements and the large, but sparsely distributed population, alternative strategies in the shape of mobile clinics could be devised with linkages both with the health facility based system and with TBAs and LHWs at the grassroot level. Linkage with NGOs for better community access and mobilisation also needs to be actively pursued and where possible successful NGO programmes could be supplemented to achieve the common agenda of health and welfare. An important first step would be to collect sufficient information about NGOs and have a concerted effort on projects.

12. Community participation mechanisms need to be carefully conceptualised with input from the NGO sector with process of implementation being given its due time. Consideration of the local community dynamics, with particular attention to the prevalent feudal structure is important in developing such mechanisms.

13. Use of a well-designed and user friendly Health Management Information Systems (HIMS) is necessary for proper planning, management and monitoring at all tiers of the health system. The issue of quality of data is inter-linked with the use of the system, therefore it is imperative that HMIS be institutionalised at both policy and managerial levels and, the existing practice of vertical implementation with emphasis only on sending reports to the national HMIS Cell, is discontinued.

14. Building of Public Health Schools and Health Technician's Schools need to be given priority over increase in medical college seats. These schools could be established at the district level and attached district civil hospitals, to provide a ready supply of locally recruited paramedics, especially female staff. A community oriented health training needs to be incorporated not only in government run medical schools but also in institutions for paramedics.

\section{B. Revamping the Population Welfare Programme}

1. It is important that the Population Welfare Programme be integrated with health outlets for enhancing coverage in the target areas. It should also coordinate and work in collaboration with vaccinators and other paramedics who are well 
trained in community mobilisation and health education techniques, and could be used as motivators to bring about attitudinal changes in the communities and religious leaders in favour of small family norms.

2. A well planned, community strategy for population welfare activities, should be formulated to create a favourable climate in the most cost-effective manner through close collaboration with the sectoral provincial departments, political and religious leaders, community level workers, social workers, NGOs and the private sector to achieve the required results. Local workers should be trained in community mobilisation and health education techniques and provided knowledge and skills in safe motherhood techniques. Besides supplying of contraceptives to the motivated persons at their door steps, the local workers need to maintain proper records of referral of clinical cases to the health facility and should provide special counseling and follow up to those families having low birth weight babies, malnourished children and mothers and defaulters of immunisation.

3. In order to motivate the people, sustainable capacity building activities related to population welfare, health education and delivery of family planning services (including monitoring and referral support) should be undertaken through continuous dialogue between the community, representatives of concerned government departments and NGOs. Those who initiate the dialogue should help in articulation of interest and felt needs of the beneficiaries, and should share their knowledge to match with the experience of the communities in the diagnostic process.

4. Providing population planning and safe motherhood services to the deprived segment of the populations should not be left to the Government alone. The community should actively participate in the provision of services with active backing from Population Welfare and Health departments. The Population Welfare Department should establish a network of community based workers by providing them training and financial and technical support while their activities could be supervised by the district committees with the help of participating NGOs. Cooperating NGOs could assist the district committee to work out a system to motivate the users and pay the cost of programme-related supplies such as contraceptives, essential drugs, ORS packets etc.

5. Training and monitoring teams, two in each district, should be constituted from amongst the Population Welfare Officers to serve as members of an integrated team consisting of one medical doctor from the Health Department and one teacher trainer from the Education Department and one Social Welfare Officer. The trainees may consist of female and male vaccinators, malaria assistants, family welfare workers and TBAs, depending upon their availability in the local BHU/RHC, Dispensary, MCH Centres, Maternity Home and Population Welfare Centre. At the initial stage, their role could be to assist the cooperating 
NGOs in setting up local organisations and later train the community based workers. The initial training may be for a short period followed by supervised practical training in the field for a longer period by a team of experts. Such areas as risks factors during pregnancy, maternal nutrition, benefits of child spacing, breast feeding, vaccination and diarrhoea management and identification of couples to provide contraceptives, should be emphasised in the initial training programme.

6. Once the initial training cycle in a district is completed, subsequent practical field training should be regularly conducted by the mobile training teams. The follow up training should be geared toward problem solving approach whereby the community workers could discuss their operational difficulties, and referral to the designated health facilities.

7. Community participation is of essential importance in any Population Welfare programme, for unless the community accepts the programme and sees it as beneficial, the chance of its success is minimal. District Committee could be the best forum for supporting and promoting population welfare activities alongwith health initiatives in an integrated manner.

\section{CONCLUSIONS}

The Health and Population Welfare Programmes in Sindh are suffering from institutional weaknesses and governance issues. People's willingness to pay for private services even in the face of financial hardship, is an indicator that government should take immediate stock of the situation and muster political will for immediate reforms.

Effectiveness of the public sector has been poor in terms of improvement of health indicators, while a meagre fertility decline can be mainly contributed to increasing age of marriage and efforts of the NGOs. Though there has been improvement in physical access through increase in the number of governmental health facilities in the rural areas over the last two decades. The perceived quality of care at governmental health facilities is poor leading to low utilisation of these facilities. Independent evaluations of outreach programmes also shows poor coverage.

Inequities exist with regard to distribution of health care across income groups, age groups and across urban-rural areas. Because of the poorly functioning governmental health system, even those in the low income groups are forced to purchase health care from the private sector or resort to self treatment. Thus the poorest who are the most dependent upon the governmental health system are the most vulnerable to its failure. Failure to perceive the health sector in its entirety during planning has resulted in urban-rural imbalances in terms of health staff and tertiary care. Lastly, no effort has yet been made towards the problems of the adult and elderly age groups, despite the new demographic realities.

On the efficiency front, under utilisation of primary care and over utilisation of tertiary care, overlapping programmes and bureaucratic delays at implementation level 
have produced gross wastages within the government's health system. There are also huge inefficiencies when looking at the overall health sector. These are due to multiplicity of providers, spiraling health expenditure due to increased spending on high technology, curative care and drugs, and implementation of parallel programmes by NGOs and the government and result from a weakened role of state in terms of policymaking and regulation.

Lastly, a culture of transparency and accountability is yet to be inculcated. The practice of political appointments even in the lowest cadres, staff absenteeism and lack of supervision, mismanagement of development funds and inept facility management has led to distancing of people from the government provided services. Within the government set up also, the service providers and mid-level managers have little say in the planning process, while the provincial hierarchy is also getting increasingly marginalised due to the dominance of the federal and donor agenda.

\section{REFERENCES}

Aga Khan University (1994) Research Information Survey, Thatta Health Systems Research Project. Karachi: Department of Community Health Sciences.

Aga Khan University (2000) Family Health Project, Sindh-An Assessment. Karachi: Department of Community Health Sciences.

Aga Khan University and Sindh Health Development Centre (1997) Family Health Project, Government of Sindh, Baseline Survey Report. Karachi: Department of Community Health Sciences.

Commission on Global Governance (1995) Our Global Neighbourhood. New York: Oxford University Press.

Federal Bureau of Statistics (1983) National Health Survey: 1982-83. Islamabad.

Federal Bureau of Statistics (1988) Census of Health Facilities. Islamabad.

Federal Bureau of Statistics (1997) Pakistan Integrated Household Survey: 1996-97. Islamabad.

Ghaffar, et al. (1999) Injuries in Pakistan: Directions for Future Health Policy. Health Policy and Planning March (1). Government of Sindh, Bureau of Statistics. 2000. Development Statistics of Sindh. Karachi.

Ghaus, Aisha et al. (1996) Social and Economic Ranking of Districts in Pakistan. Karachi: Social Policy and Development Centre.

Green, Andrew, Mohammed Rana, and Duncan Ross (1997) Health Planning in Pakistan: A Case Study. International Journal of Health Planning and Management 12: 187-205.

Human Development Centre (1999) Human Development in South Asia, 1999. The Crisis of Governance. Oxford: Oxford University Press.

Karim, Mehtab S. (1999) Effects of Migration, Socioeconomic Status and Population Policy on Reproductive Behaviour. London School of Economics, Asia Research Centre, London. (Discussion Paper.) 
Karim, Mehtab S., Syed Iqbal Azam, and Amyn B. Lakhani (1998) Maternal and Infant Mortality Survey-Sindh. Report of Household Socio-economic, Demographic and Maternal Health Conducted in Sindh Province in 1994. Department of Community Health Sciences, The Aga Khan University, Karachi.

Ministry of Population Welfare and The Population Council (1995) Situation Analysis of Village Based Family Planning Workers in Pakistan. Islamabad. (Research Report No. 3.)

National Institute of Population Studies (1991) District-wise Population of Pakistan. (Wall Chart). Islamabad.

National Institute of Population Studies (1992) Pakistan Demographic and Health Survey: 1990-91. Islamabad.

Pakistan Medical Research Council (1998) Health Profile of the People of Pakistan, National Health Survey of Pakistan 1990-94.

Pakistan, Government of (1972) 1972 Census Report. Islamabad: Population Census Organisation.

Pakistan, Government of (1981) 1981 Census Report. Islamabad: Population Census Organisation.

Pakistan, Government of (1998) Second Social Action Programme Project. SAPP II. Federal Areas, Federal Programmes and Provincial Programmes. AIDE Memoire. Volume II, 4 August.

Planning and Development Department (1990) Survey of Basic Health Units and Rural Health Centres in Sindh to Assess the Building Utilisation. Karachi: Sindh Regional Plan Organisation. Government of Sindh.

Population Council Pakistan (1998) A Study of the Operations of the Contraceptive Logistics System of the Population Welfare Programme. Islamabad. (Research Report No. 8.)

Ruknuddin, A. R., and K. Cleveland-Hardee (1992) Can Family Planning Succeed in Pakistan. International Family Planning Perspectives 19:4.

Selier, Fritz, and Mehtab S. Karim (1986) Migration in Pakistan. Lahore: Vanguard Books.

Social Policy and Development Centre (SPDC) (1998) Social Development in Pakistan, Annual Review. Karachi: Oxford University Press.

Social Policy and Development Centre (SPDC) (1999) Social Development in Pakistan, Annual Review, Social Development in Economic Crisis. Karachi: Oxford University Press.

Streeten, P. (1997) Non-governmental Organisations and Development. ANNALS 554.

World Bank (1994) Governance: The World Bank's Experience. Washington, D. C.

World Bank (1997) Pakistan - Towards a Health Sector Strategy. Health, Nutrition and Population Unit, South Asia Region, Washington, D. C. (Report No. 16695.) 


\section{Comments}

The authors of the paper have addressed the critical question of how poorly the health and population welfare programmes in Pakistan have performed over the years and what problems exist in the service delivery mechanisms of the two sectors. The paper gives a comprehensive review of the health and family planning services, with particular focus on Sindh province. In this context, a host of problems faced by the government's health and population welfare facilities network in the province have been discussed including the poor quality of services, their limited access and availability, inadequate training of manpower and staffing of health outlets, budgetary constraints and inefficient management of the health system and population welfare programme.

I strongly share the concerns of the authors regarding the inadequacies in health and population services in the public sector. As many of us know that health and population as part of social sector development have been given low priority in terms of budgetary allocations and the limited funds have not been used effectively and efficiently. Given this, I would focus my comments on the approach undertaken in the paper to analyse the issue in question.

Health network in Pakistan is a complex set up comprising public, private and NGO sectors which operate at different levels in the cities, towns, peri-urban and rural areas. Although the paper illustrates some important statistics and performance indicators of different service outlets and health projects, it lacks a coherent approach to assess the actual situation in a holistic manner. The analysis presented gives a disjointed picture of the issues at hand and touches upon a variety of problems in a partial manner. If the objective of the paper is to examine the performance of health and population programmes from the governance perspective, it would have been better to use some criteria or indicators of good governance to show how and in what way the two sectors were affected.

The authors have focussed heavily on health and population issues in the public sector, whereas a substantial part of health services are contributed by the private sector. No attempt, however, is made to show how the extensive network of health facilities in the private sector is affecting the utilisation and performance of public health care system. As is observed, a significant proportion of population and health service providers in the public sector is also engaged in providing services in private clinics, it would be useful to see what approach could be adopted to build up partnership of the two and maximise the utilisation of health facilities network. In this regard, it would be useful to discuss in the paper as to what factors are keeping the utilisation rates lower in the public sector. 
The later part of the paper has proposed specific strategies to revamp the health care system and population welfare programme in the Sindh province. Although the recommendations made are relevant and reform-oriented, the question still remains of improving their implementation and good governance. For example, the suggestion to integrate population welfare services with health outlets and develop community participation for enhancing coverage in the target areas is valid, but there is no mention of what mechanisms would be appropriate for implementing this strategy.

My final comment relates to the peculiar situation in Sindh-a province with the highest level of literacy and urban population, yet showing poor health and demographic indicators. There is a need to analyse what factors have contributed to this poor performance in both the sectors. In this context, the authors have not mentioned the law and order, peace and security situation prevailing in the province which are important factors in affecting the performance of the service delivery mechanisms in the two sectors.

In the end, I would like to reiterate my point that the paper has raised some important issues of concern and has proposed relevant strategies to improve the present service delivery set up in the health and population sectors. The paper, however could be improved by adding in the missing links and undertaking a focussed analysis of the issues under study.

Pakistan Institute of Development Economics,

Naushin Mahmood Islamabad. 